\title{
Electrical Conductivity of Natural Volcanic Tuff Mix by Cyclic Voltammetry Method
}

\author{
Ahmad Khalaf Alkhawaldeh \\ Department of Pharmaceutical Chemistry; College of Pharmacy, Jerash University, Jordan. \\ E-mail: Ahmad.alkawalda@yahoo.com
}

Phone: 00962787455167

\begin{abstract}
:
This paper has experimentally measured volcanic tufa electrical conductance. The calculations are carried out in accordance with the potential of cyclic voltammetry in a constant state. The cyclic voltammograms nanoelectrode platinum prepared electrochemically were examined in the range -0.2 to $1.2 \mathrm{~V}$ vs. $\mathrm{AgCl}[\mathrm{Cl}-$ ]:1.0 $\mathrm{M}$ in the presence and absence of volcanic tuff in the aqueous solution of $1.0 \mathrm{M} \mathrm{HCl}$. The cyclic voltammetry studies show that the Nano platinum film suffers degradation when the potential exceeds $+0.85 \mathrm{~V}$, and below this potential, it is quite stable. The redox reaction of the electrode is reversible. The nanoparticle platinum synthesized at low temperature and high acid concentration exhibits higher electronic conductivities. It has been observed that, relative to area under the peak aggregate tests, the use of volcanic concrete was showing a large increase in electrical conductivity. It was shown that with cyclic voltammetry, three well-defined anode peak could be achieved at a power of $0.0,0.4$ and $0.6 \mathrm{~V}$ versus $\mathrm{Ag} / \mathrm{AgCl}$.
\end{abstract}

Keywords: Electrical conductivity, volcanic tuff, Cyclic Voltammetry, Conductivity Nanoparticle, Platinum Electrode.

\section{Introduction}

Building is using a large quantity of natural resources. Due to population growth and industrialization, the market is rising annually. This growing environmental and natural resource pressure and the use of new construction materials has been an enticing choice to tackle the demand-supply gap. Volcanic tufa is one of the old construction materials used for low costs and lightweight quality (Al-Harahsheh. et al., 2014).

The electrical quality of building materials is one of the key considerations, especially in the extreme environment where temperature has a profound effect on human health and well-being (Krishan, et al., 2019). In general, electrical conduction is the simplest, as the Fourier Law merely states that the thermal energy transmitted in a particular direction by conduction in each unit region is proportionate to the temperature gradient to that effect (Alkhawaldeh et al, 2020).

Electrical conductivity is the proportionality parameter in this regulation and the symbol is implied. Thermal conductivity is a physical feature of the substance with certain materials with a uniform nature, based primarily on temperature, pressure and nature. The thermal conductivity in the solid state can therefore depend on the heat flow directions (Hourani and Alkawaldeh, 2016).

Both three types of heat transfer are present in realistic conditions, which complicate the heat conductivity calculation cycle. Work in the field is therefore significantly incorrect and measuring methods to clearly assess thermal conductivity have been quite difficult to establish. In comparison, electrical 
conductivity is highly anisotropic for many sedimentary and metamorphic rocks, so lateral heat flow would be important. Anisotropic data are also required and laboratory measurements are necessary in various direction (Al-Zboon, et al., 2016).

The thermal conductivity of a variety of rocks is still anisotropic and also high, whether the rocks are subjected to demise or other tectonic processes the thermal Conductivity of the resulting rock collection can either be isotopically or anisotropic ally. Any anisotropic foundations in other respects, even on a microscopic lot of minerals are anisotropic (Gündüz, and Kalkan, 2020).

The electrochemical electrical conductivity monitoring techniques such as polarization techniques, potentiometric methods, and galvanic sensors are complicated and require particular expertise in using nitrogen gas for isolation the solutions from oxygen (Balog, et al., 2014).

Unlike the previous electrochemical techniques, the electrical conductivity method is available, simple, and not affected by oxygen pressure and its results are easy to interpret (Altwaiq, et al., 2015). This study aims at measuring the variations of electrical conductivity of volcanic tuffs by cyclic voltammetry and chronoamperometric in $1.0 \mathrm{M} \mathrm{HCl}$ solutions.

\section{Experimental}

These samples were collected from several locations of the outcrop. They were crushed and sieved to the desired size, a size fraction of $125-250 \mu \mathrm{m}$ was used in this study. First, the samples are homogenized, weighed to the nearest $0.1 \mathrm{~g}-5 \mathrm{~g}$ of well-mixed Volcanic Tuff sample in porcelain dish. Nitric acid (HNO3) $67 \%$ for Trace analysis was purchased from Fluka Company (Switzerland). Solutions of $1.0 \mathrm{M} \mathrm{HCl} \mathrm{were}$ prepared from concentrated $\mathrm{HCl}$ solution that was purchased from Merck (UK). All solutions used were made from the above-mentioned reagents dissolved in Milli-Q water (Millipore, Merck).

A potentiostat (273A) and Feature Generator (Simpson Model 420 A) interfaces with a laptop for the electronic control and data collection. Electrochemical cells (H-forms) with nitrogen purging solution were used. The operating electrode was a $1.00 \mathrm{~mm}$ diameter electrode and a Platinum plate (99.95\% solid, healthy fellow METALS). Platinum is used to create auxiliary and working electrodes (Johnson Matthy, 99.99\% cleanliness). The relation is an electrode ( $\mathrm{Ag} / \mathrm{AgCl} /[\mathrm{Cl}-]: 1.0 \mathrm{M})$. An electrode is stated for both potentials.

The electrical conductivity of the investigated solutions was measured using CC-501 conductometer (Elmetron, Witosa, Poland). The meter is equipped with custom LCD, which enabled simultaneous observing of the measured function and temperature. The electrical conductivity meter contains temperature compensation mode and internal data logger for 200 measurements with time date and temperature. The conductometer co-operates with Pt-1000 temperature probe with Chinch connector.

\section{Results and Discussion}

The SEM micrograph with E potential $=14.5 \mathrm{~V}$ is seen in Figure 1. The powder layer showed a well separated, homogeneously dispersed porous nanostructure over the earth. It is confirmed by the EDX sequence of nanostructure platinum electrode, indicating the usual diffraction peaks. 


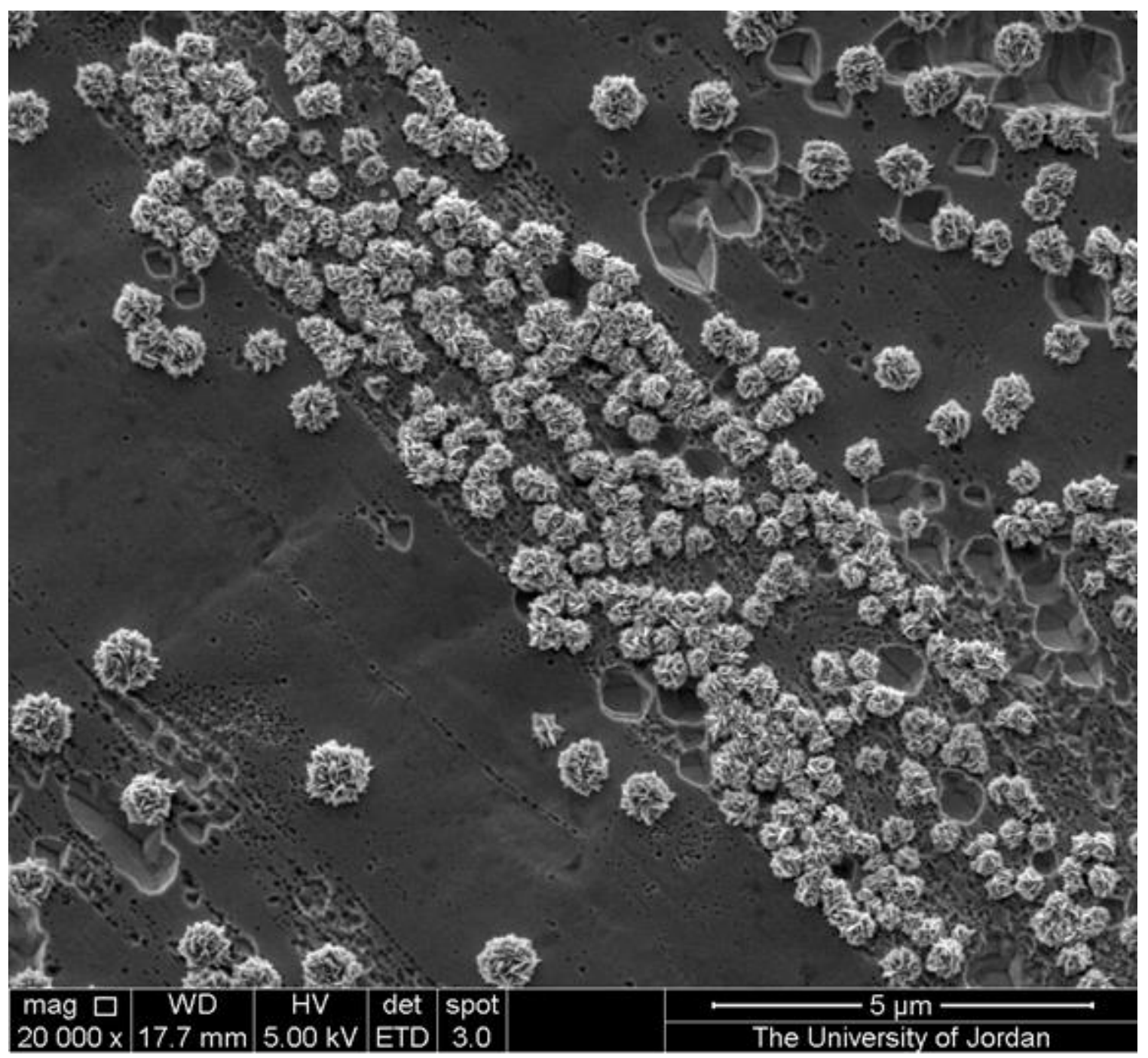

Figure 1. Scanning electron micrograph of platinum nanoelectrode.

The measured electrical conductivity values for the five specimens as described above are shown in Figure 2. The spectrum of heat conductivity values ranged from 2.4 to $0 \%$ for tuff and from 1.9 to $100 \%$ for tufts for the different Tuff formulations. Tuff increases thermal conductivity, with a tufa ratio of $100 \%$, of $19.16,8.75,7.91$ and $3.33 \%$, respectively, to $75 \%$, and $25 \%$, compared to normal aggregate samples.

The high power conductivity of tuff specimens can be due to the high content of other materials, such as platinum electrode, which are more than $21 \%$ by weight of volcanic tufa specimens while over $97 \%$ is $\mathrm{CaO}$. By comparing volcanic tuff composition content electric conductivity values with other common building materials, low thermal conductivity for the specimens tested was found. It shows that this constructed substance is much safer than other isolation materials and a strong heat storage medium because of the rapid release of accumulated energy in comparison to concrete materials. 
In the first experiment, the stable conditions achieved as initial conditions were used for subsequent cases. For increasing electrical conductivity value of the particular specimen various steady states were observed. In addition, dissimilar temperature levels were pushed by each heat transfer rate. Dissimilar electrical conductivity values will then be obtained based on temperature ranges.

The present temperature distribution values are, however, dependent on the proper stable conditions as the test equipment's capacity and input power. In the other hand, diminishing variations in thermal conductivity based on the temperature level guarantee the exact findings picked.

Results for the temperature distribution of the selected experiments are presented in table1.

Tables 1 Values of Conductivity and the temperature distribution for the tested specimens

\begin{tabular}{|l|c|c|}
\hline PH & Temperature $\left({ }^{\circ} \mathbf{C}\right)$ & Conductivity (s cm-') \\
\hline 1 & 25 & 180 \\
\hline 2 & 25 & 96 \\
\hline 3 & 25 & 85 \\
\hline 4 & 25 & 74 \\
\hline 5 & 25 & 80 \\
\hline 6 & 25 & 200 \\
\hline
\end{tabular}

The ratio of $25 \%$ of the concrete tuff applied will minimize concrete's weight by $5,8 \%$ in Figure 3 and the electrical conductivity by 3,33\% in Figure 3. Similarly, a reduction of $8.2 \%$ in concrete weight by a tuff ratio of $50 \%$ is achieved while electrical conductivity increased by $7.9 \%$.

At a higher tuff ratio, the concrete density decreased marginally $(-13,3 \%)$, while the power output increased dramatically $(19,1 \%)$. Higher tuff aggregate density encourages the use of this material, in particular as a lightweight concrete with suitable insulation properties in the building industry.

Physical, chemical and structural characteristics of material have strong effect on its thermal conductivity. To explain that, EDX for natural volcanic tuff were determined previously [Al-Zboon et al., 2015]. The EDX analyses showed that phillipsite and chabazite are the main predominant rocks. Deposit also appeared significantly at many theta.

According to the $\mathrm{EDX}$ analyses, natural volcanic tuff consists of $\mathrm{SiO}_{2}(45.33 \%), \mathrm{Al}_{2} \mathrm{O}_{3}(11.32 \%)$, $\mathrm{Fe}_{2} \mathrm{O}_{3}$ (10.44\%), $\mathrm{CaO}(10.57 \%), \mathrm{MgO}(7.97 \%), \mathrm{TiO}_{2}(2.77 \%), \mathrm{Na}_{2} \mathrm{O}(2.01 \%), \mathrm{K}_{2} \mathrm{O}$ (1.37\%) with LOI of $8.22 \%$. Normal aggregate used in the control sample consist of limestone with $97.4 \% \mathrm{CaO}$. Electric transport of porous rocks depends, as is well known, on their shape, mineral composition, density, porosity, and capacity to conduct heat and temperature on their constituent minerals. 


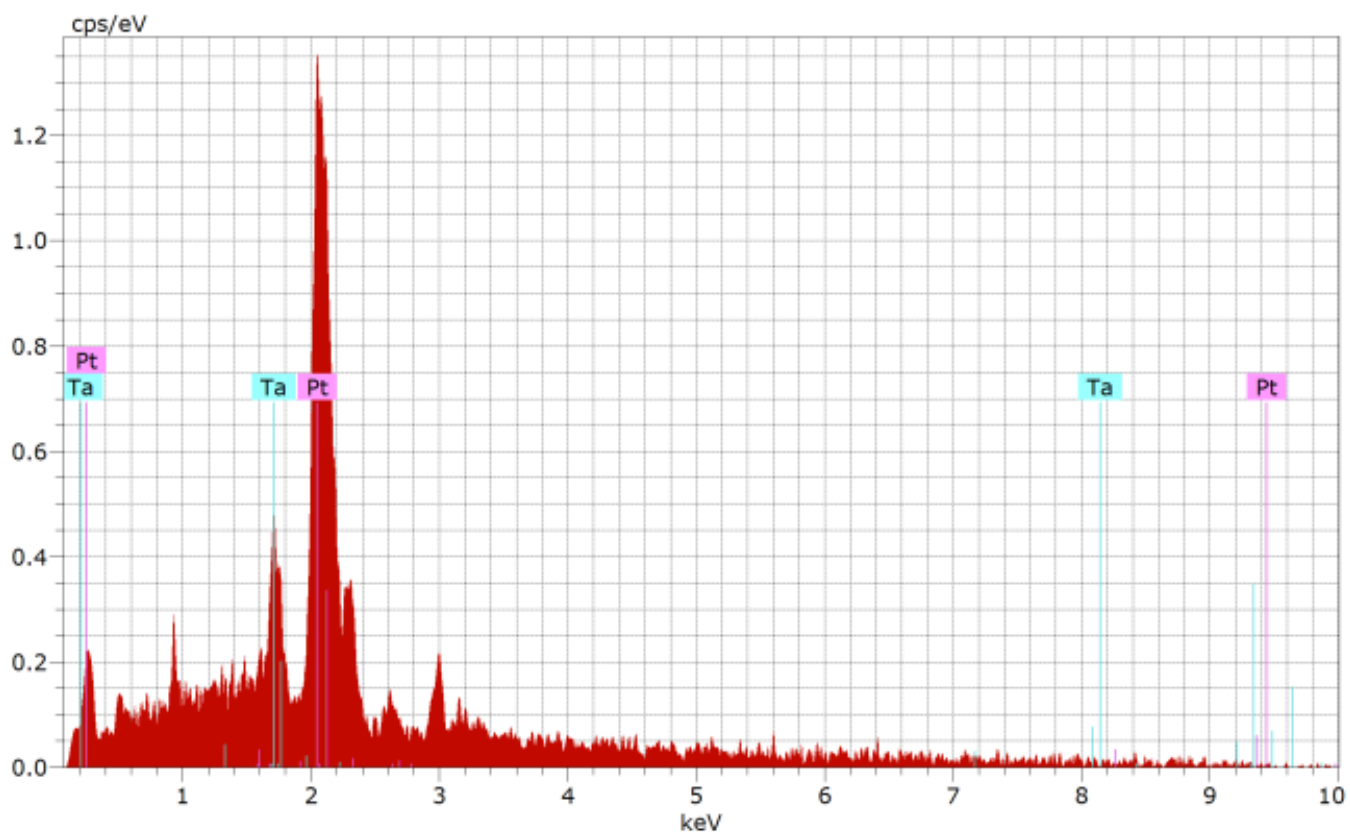

Figure 4. Cyclic voltammograms of platinum nanostructure at different concentration in the solution.

Figure 5 indicates the platinum electrode concentration of Volcanic Tuff. With cyclic Voltammetry $(\mathrm{CV})$, the voltammograms were obtained at an appropriate scan rate of $100 \mathrm{mV} \mathrm{s}$. Before a preconcentration phase in Volcanic Tuff, the base curve, showing no point, was obtained. As shown in Figure 4, after the pre-concentration phase the peak current revealed that the Volcanic Tuff had been removed from the bulk solution by platinum nanoelectrode. 


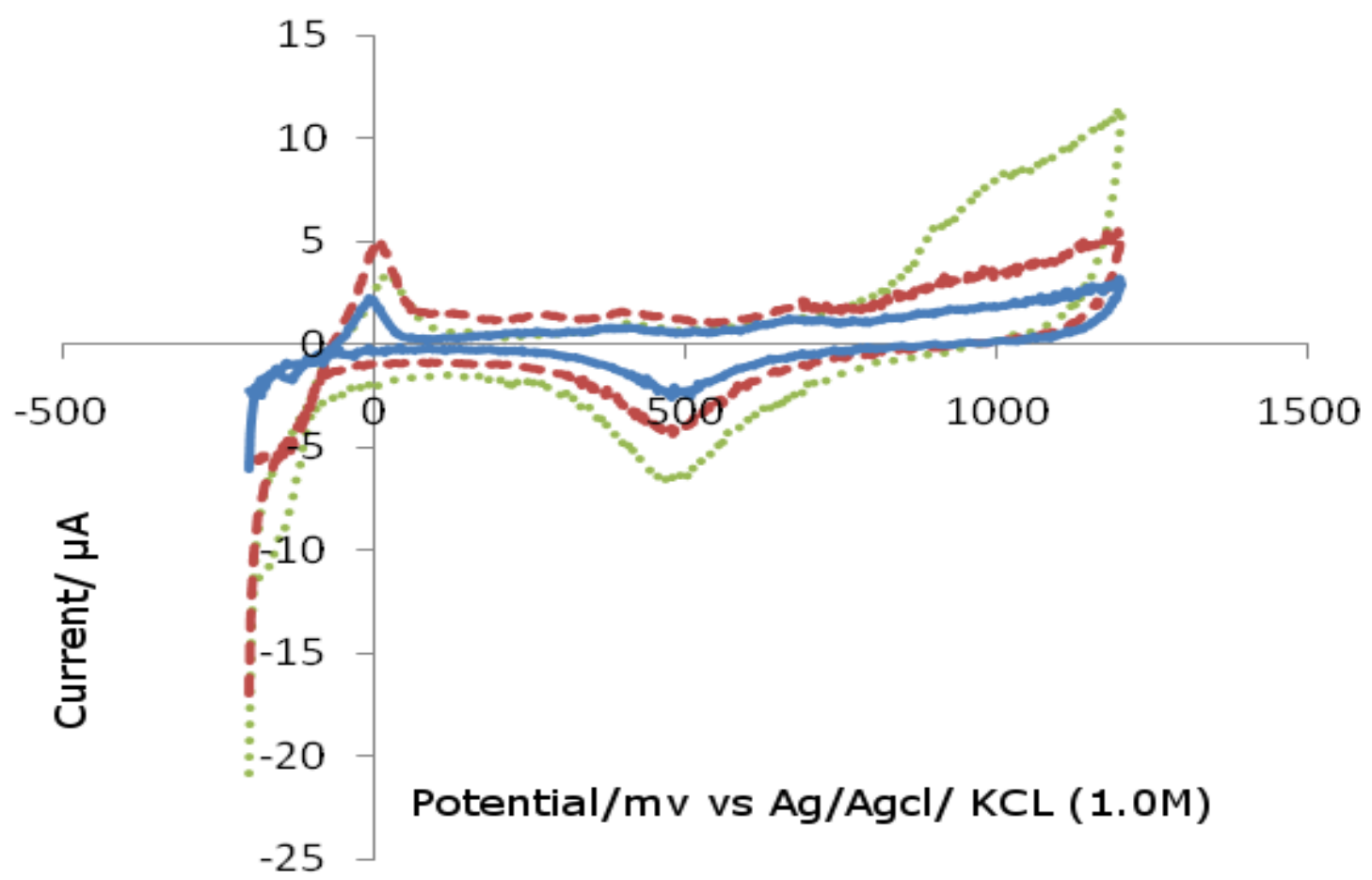

Figure 5. Cyclic voltammograms of nanoparticle platinum electrode before and after incubation with Volcanic Tuff. During $30 \mathrm{~min}$; supporting electrolyte is $1.0 \mathrm{M} \mathrm{Hcl}$; the scan rate was $100 \mathrm{mV}$ s-1 at different $\mathrm{PH}$.

The electrochemical cyclic voltammetry of platinum is believed to proceed via the cation radical. The anodic oxidation of Volcanic Tuff in the $1.0 \mathrm{M} \mathrm{HCl}$ solution gives a radical cation that couples in a head-to-tail manner.

The voltammetric activity of the volcanic tuff solution was studied in the acidic solution. Shows multiple cycled solving voltammograms with potential ranges -0.2 and $1.2 \mathrm{~V}$. With potential numbers of scans, the redox peak currents gradually rose, indicating that volcanic tuffs were formed, with potential cycling thickness increased. Both rates of oxidation were high and, negative, with intervals, diminishing rates.

When the possible scan did not reach $0.85 \mathrm{~V}$, the middle redox peaks did not occur as seen in Figure 5. With a rising volcanic tuff accumulation, the amount of the middle redox peak currents decreased. With the rise in scan speeds, the redox peak currents rise. The anodic peak currents are strong and higher indicating the conductive state of the volcanic tuff. On the other hand, the catholic high currents, which signify the transition of Volcanic Tuff into an electrically isolated reduced state, are narrower and larger than the anodic highest currents.

\section{Conclusions}

In Jordan, the lack of building materials can be substituted by a volcanic tufa in significant amounts. This thesis aimed to examine the impact of natural tuff materials on the electric output of concrete 
samples. There are findings showing that the electrical conductivity of volcanic composite tuff varies from 1.9 to $0 \%$ and from 2.4 to $100 \%$ of the tuff. In addition, a decrease of the cement content of the volcanic aggregates to $13 \%$ in the study of $100 \%$ pipeline, suggests an increased conductivity of $19.1 \%$. The results are summarized in Table 1 . The conductivity of the film increases with the decrease of solution $\mathrm{pH}$ and Volcanic Tuff temperature used to synthesize the nanoelectrode. It was shown that with cyclic voltammetry, three well-defined anode peak could be achieved at a power of $0.0,0.4$ and $0.6 \mathrm{~V}$ versus $\mathrm{Ag} / \mathrm{AgCl}$.

\section{References}

Alkhawaldeh, A. K., M.Krishan, M., Altwaiq, A., Dabaibeh, R. N. (2020). Preparation of Nanostructured/ Microplatinum Surfaces by Application of a Square Wave Potential Regime for Methanol Oxidation. Eurasian Journal of Analytical Chemistry, 15(1), emEJAC-00362.

Almatarneh, M. H., Elayan, I. A., Al-Sulaibi, M., Khawaldeh, A., Saber, S. O. W., Al-Qaralleh, M., and Altarawneh, M. (2019). Unimolecular Decomposition Reactions of Propylamine and Protonated Propylamine. ACS Omega, 4(2), 3306-3313. doi: 10.1021/acsomega.8b02792.

Alshamaileh, E., Al-Sulaibi, M., Al-Khawaldeh, A., Almatarneh, M., El-Sabawi, D. and Al-Rawajfeh, A. (2016), "Current status of nanotechnology in Jordan", World Journal of Science, Technology and Sustainable Development, Vol. 13 No. 2, pp. 66-81. https://doi.org/10.1108/WJSTSD-01-2016-0001.

Altweiq, A. and Alkhawaldeh, A (2019). The Determination of Some Heavy Metals in Different Selected Diets. Eurasian Journal of Analytical Chemistry, 14(4), emEJAC-00326.

Hourani, M. K. and Alkawaldeh A. (2016). Synergistic Effects of Bismuth Adatoms on Electrocatalytic Properties of Electrodeposited Nanostructured Platinum Electrodes. International Journal of Electrochemical Science, 3555-3566. doi: 10.20964/110434.

Krishan, M.; Alkhawaldeh, A.; Soliman, A. (2019). Development of Nitride-Sensors for Monitoring in Control Systems. Preprints, 2019050227.

Al-Harahsheh, M., Shawabkeh, R., Batiha, M., Al-Harahsheh, A., \& Al-Zboon, K. (2014). Sulfur Dioxide Removal using Natural Zeolitic Tuff. Fuel Processing Technology, 126, 249-258. doi:10.1016/j.fuproc.2014.04.025.

Al-Zboon, K. K., Al-Smadi, B. M., \& Al-Khawaldh, S. (2016). Natural Volcanic Tuff-Based Geopolymer for Zn Removal: Adsorption Isotherm, Kinetic, and Thermodynamic Study. Water, Air, \& Soil Pollution, 227(7). doi:10.1007/s11270-016-2937-5.

Gündüz, L., \& Kalkan, Ş O. (2020). Lightweight Cellular Hollow Concrete Blocks Containing Volcanic Tuff Powder, Expanded Clay and Diatomite for Non-Load Bearing Walls. Teknik Dergi. doi:10.18400/tekderg.426034.

Balog, A., Cobîrzan, N., Aciu, C., \& Iluţiu-Varvara, D. A. (2014). Valorification of Volcanic Tuff in Constructions and Materials Manufacturing Industry. Procedia Technology, 12, 323-328. doi:10.1016/j.protcy.2013.12.493. 
Altwaiq, A., Abdel-Rahem, R., Alshamaileh, E., Al-luaibi, S., and Khouri, S. (2015) Sodium lignosulfonate as a friendly-environment corrosion inhibitor for zinc metal in acidic media. Eurasian Journal of Analytical Chemistry. 10, 10-18.

Al-Zboon, K. K., \&amp; Al-Zou'By, J. (2015). Effect of volcanic tuff on the characteristics of cement mortar. European Journal of Environmental and Civil Engineering, 20(5), 520-531. doi:10.1080/19648189.2015.1053151

Al-Zboon, K. K., Al-Zouby, J. Y., \&amp; Al-Tabbal, J. A. (2017). Low-Cost Treatment Of Grey Water And Reuse For Irrigation Of Home Garden Plants. Environmental Engineering and Management Journal, 16(2), 351-359. doi:10.30638/eemj.2017.035

Azzam, M. O. (2018). Olive mills wastewater treatment using mixed adsorbents of volcanic tuff, natural clay and charcoal. Journal of Environmental Chemical Engineering, 6(2), 2126-2136. doi:10.1016/j.jece.2018.03.009 